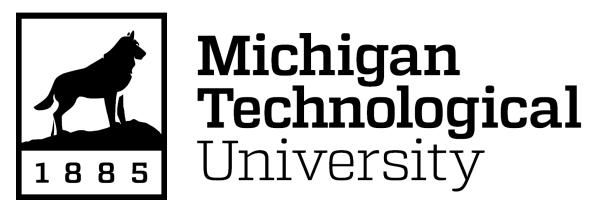

Michigan Technological University Digital Commons@ @ichiganTech

6-5-1970

\title{
Community Relationships and Population Dynamics of Terrestrial Mammals of Isle Royale, Lake Superior, 1969-1970
}

Wendel J. Johnson

Purdue University

Michael L. Wolfe Jr.

Purdue University

Durward L. Allen

Purdue University

Follow this and additional works at: https://digitalcommons.mtu.edu/wolf-annualreports

\section{Recommended Citation}

Johnson, Wendel J.; Wolfe, Michael L. Jr.; and Allen, Durward L., "Community Relationships and Population Dynamics of Terrestrial Mammals of Isle Royale, Lake Superior, 1969-1970" (1970). Ecological Studies of Wolves on Isle Royale. 52.

10.37099/mtu.dc.wolf-annualreports/1969-1970 
CORRUNITY RELATIONSHIPS AND POPULATION DYNAPIICS

OF TERRESTRIAL NIAIAIALS OF ISLB ROYALE, LAKE SUPERIOR*

Fourth Annual Report

(Covering the Twelfth year in the Isle Royale studies)

$1969-70$

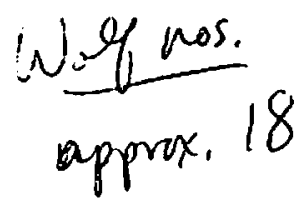

by

Piendel J. Johnson, Graduate Research Assistant

Michael L. Wolfe, Jr., Research Associate

Durvard L. Allen, Professor of Vildlife Ecology

Department of Forestry and Conservation Purdue University

Lafayette, Indiana 47907

5 June 1970

* Receiving principal support durlng the current year from the National Science Foundation (GB-5124), the National Park Service, and the Wildlife Vianagement Institute. 
STUDIES OF ISLE ROYALE MALRAA POPULATIONS

This report terminates the current four-year phase of the Isle Royale studies. Wendel Johnson completed his academic program on the campus in August and submitted his thesis, major findings of which will be summarized here, pending their publication. In September, Johnson assumed duties on the staff of the University of Wisconsin at liarinette.

Hichael Wolfe left his post-doctoral position on this work in mid-February for a teaching-research appointment on the staff of Utah State University. Rolf 0 . Peterson, of the University of lifnnesota, Duluth, will begin work on the wolf and its prey in June 1970. This is expected to be a three-year $\mathrm{Ph}$. D. assignment.

The work schedule of 1969-70 was much like that of former years. Michael Wolfe and lifchael $\mathrm{N}$. Kochert arrived on the island on 20 lay. Kochert, a January graduate of our wildlife curriculum, helped in the field until $12 \mathrm{July.} \mathrm{Ronald} \mathrm{L.} \mathrm{Bell} \mathrm{and} \mathrm{Steven} \mathrm{H}$. Ruckel finished their junior year in vildlife studies and reported to the island as summer assistants on 2 June. They left on 24 August. These men carried on the work durfing Wolfe's absence from 5 August to 29 September. From the latter date, the fall work continued until 26 october. During the last two weeks, Larry J. Roop went off the park summer payroll and assisted in our work.

From 3 to 23 October, Philip C. Shelton, on leave from the Smithsonian, made a fall survey of the beaver population. This was his first review of the situation since he finished his $\mathrm{Ph} . \mathrm{D}$. project in 1963. Results of the 1969 work are included in this report. A contribution also was made by Jim A. Bottorff, who carried out an undergraduate research project on moose aging.

Again this year, an attempt was made to open the winter camp a week early. Wolfe, accompanied by John $C$. Keeler as assistant, went north on 23 January, planning to fly to the island on the $24 \mathrm{th}$. They were delayed by bad weather in Virginia, liinnesota, and finally vere able to fly to hashington Harbor on the 29th. Pilot Donald E. Murray and park electronics technician Willido Dohrn made up the party of four. Transportation flights vere made this winter, as usual, by William E. liartila in the Cessna 180. The first two weeks of the winter study were marred by the illness of Holfe and Murray, with respiratory infections. Allen arrived on the Island 14 February and closed camp on 14 liarch. Holfe left the island on 17 Bejrucry and Keeler left for airforce training on 7 March. Our pilot and volf observer Don Murray is the old-timer of this project, 1970 marking the 12th winter he has been on the island flying the Aeronca Champion in pursuit of the wolves. 
Films taken in February 1969 by the MGi-Canadian Film Board team vere included in the NBC television broadcast entitled "The wolf men," on 18 November. This program, assembled and directed by Irwin Rosten, of MGM Documentary Division, probably stimulated more continent-wide interest in the wolf than any other event in history. In our Purdue office more letters were received than could be handled individually, so a form letter was used, which is attached as an appendix to this report.

There was some hope that the increased publicity might turn up a financial sponsor for this research program, although that has not happened as yet. In December 1969 the remainder of our fourth National Science Foundation grant was expended. Currently ve are receiving support from the National Park Service and the Wildlife lianagement Institute and are expecting to operate on a considerably restricted budget for the next three years.

\section{The Hinter Study, 1970}

After two vinters of extreme veather conditions-- the least snow we have experienced in 1963 and the heaviest in 1969-- things were back more nearly to normal in 1970. When the party first measured snow depth on 31 January, there vere 23.2 inches in the voods. On 2 liarch the average depth was 21.8 inches. Approximately 10.75 inches of new snow fell in the 6-veek period. liost of this was light and fluffy but created reasonably good tracking conditions on February 5, 10, and 27. On 3-4 Warch a day-long rain followed by icing created some of the vorst conditions we have seen for this work. Subsequently, a hard crust formed and wolves could not be tracked for the last two weeks of the work.

The principal feature of winter weather in 1970 was high winds. Many times on relatively clear days the air was too rough for the kind of low-level-flying that is necessary for our observations. As a result, total flying time in 1970 was only 90 hours and 23 minutes, which is the least we have ever had in a winter period. The mean daily maximum temperature recorded was $+22.27^{\circ} \mathrm{F}$, and the mean minumum vas $-1.34^{\circ} \mathrm{F}$. Then the party flew over on 31 January, there was continuous ice from the island to Canada, the western edge describing an arc from Huginnin Cove to the islands off Pigeon Point. After the third reek in February, open spots appeared and developed into extensive leads after the first of liarch.

The vinter was a poor one for seed-eating birds. A few small groups of redpolls were seen, and they were feeding principally on the seed of upland alder (A. crispa). The large flocks of siskins and redpolls that appear in a year of abundant birch seed were missing. Likewise, there was no fruit on the mountain ash, and the grosbeaks vere missing, although a few red crossbills were seen. Since mountain ash fruited heavily last summer, it may be assumed that this scarcity, perbaps of all tree fruits and seeds, was due to an early ice storm. 
Woodpeckers were exceptionally plentiful, especially hairy and downy. Pileated woodpeckers were heard frequently, and one arctic threetoed was recorded. Horned owls were heard rarely, and one juvenile bald eagle was seen. A few ducks, evidently all mergansers and goldeneyes, were observed beyond the Ice around the vest and south shores.

A new major finding of the winter was the sighting by pilot liurray and ranger Zeb Jickinney of a cat on the ice of Lake Richie on 8 liarch. Later Allen and hurray examined and measured the tracks and decided that it was a lyns. This confirms occasional sumer reports of cat observations over the past several years.

\section{The Nolf Population}

A sumary of volf observations for the past winter indicates a total population of approximately 18 , as compared with an estimate of 17 last winter. The la pack was 8 (sometimes 7), and smaller groups of non-breeders numbered 4,3 , and 2 . One loner was accounted for, and there may have been two.

Tro years ago, a pack of 6 wolves containing two black individuals disappeared and has not been seen since. We hypothesize that these animals vent back over the ice to Canada. A year later, in 1969, our large pack, which contained a breeding pair, vas 8 most of the time, after an initial and perhaps questionable count of 9 . This pack contained a black animal-- and another so dark it might have been the fourth of the original four blacks that came over from Canada in 1967. This is obviously the "big" pack of 8 we observed frequently in 1970.

Because of the exceptionally deep snow of 1969, an unusually large number of partially eaten moose carcasses remained on the range at the end of winter. It appeared that, with these available as a food supply, conditions were outstandingly favorable for the production of pups in spring. Actually, the expected increase in the island wolf population did not occur, although a litter appears to have been born. On 31 January, on the shore of Rock Harbor across from the Nott Island headquarters, Wolfe and lifurray found the remains of a pup-- partly eaten by foxes but not yet completely frozen. It is possible that another young animal was in th pack of 3 , but this is uncertain, and we can not confirm the existence of any living pups on the island at the end of the winter study.

The social structure of the big pack had several obvious

features: The dominant volf was a large gray male who, through late February and two veeks of liarch, was consistently attending an extremely small female. Closely associated with this pair was the large black male, who ran and rested with them, making it easily recognized trio. The black male obviously deferred to the gray breeder, 
using all the postures of social inferiority, and was tolerated thereby as a close companion. The black male probably can be considered the beta male of the pack. The social status of 3 of the remaining 4 was not evident. However, the fourth animal was the low wolf in the social ordex. It usually maintained a distance of 30 to 50 yards from the others, and commonly it stood respectfully with its tail tucked. Although copulation was not observed this vinter, there is little doubt that there will be a breeding den and a litter born somewhere on the island in the spring of 1970 .

The large pack, containing the blacle wolf, was not located this vinter until February 19, at which time only 6 animals vere seen. Thus our largest group of wolves escaped discovery for three weeks, illustrating the fallibllity of our observations relative to any complete count in a short time. It is true, however, that Wolfe and lurray spent most of their flying time in the first two weeks in the moose census, and we have no doubt that under normal conditions our pilot could have unraveled the track puzzle and 10cated the big pack somewhat earlier in the period. The group of 8 wolves used the vestern half of the island, but restricted flying opportunities foreclosed a better estimate of their occupied area or the number of kills for which they were responstble in the total of 22 that vere found.

of the smaller group of wolves, 2 (frequently only one) were in the Hashington Harbor - McGinty Cove area, 4 vere in the Richie-Chickenbone-Todd Harbor region, and 3 were found in the northeast sector around Duncan Bay and Amygdaloid Island.

During the vinter period $18 \mathrm{kills}$ or partial remains were examined on the ground, of which 6 vere calves of the year. Tro calves that must have been killed at about the same time were found on i.jcGinty cove and may have been a pair of twins. No previous record of this kind has been found in the Isle Royale studies. Of the four remaining kills, which vere discovered from the air but not examined on the ground, one vas on the ice of the sath shore, and attempts will be made in June to find the other three. 
Moose Numbers and Losses

In the years of this study several methods have been used in monitoring the size of the moose herd, the first being a winter count covering the entire island by David liech in 1960. This is not feasible because the weather conditions under which it is possible occur so seldom as to be phenomenal. Peter Jordan developed a stratified sampling system for the winter count and a system of pellet plots to be used as an index of wintering populations-- work continued by lifichael bolfe. The results of pellet counts need to be converted to population figures in terms of the defecation rate of an average moose over 24 hours in vinter under Isle Royale conditions, and this information has not been available. We have attempted to obtain a cow:calf index in summer as a comparative measurement of annual breeding productivity, and a fall "antler and calf" count has been taken after the leaf fall in late October. The great problem in applying any of these methods has been to obtain unbiased samples of sufficient size. In general, it may be stated that our inventories have been subject to disconcertingly large errors.

Since it is seldom possible to begin field work in the park before mid-jay, and our student help is not ordinarily available before early June, the period for running pellet lines before the growth of nev vegetation is relatively short. Holfe and Michael Rochert began the rork on 23 May 1969, with later assistance by Bell and Ruckel. The running of 83 percent of the transects for the eeason represented a reasonably good sample under the circumstances.

Pellet line figures since 1964 have been converted experimentally to population estimates by applying a moose defecation rate of 11.9 times per day, as reported by Plerre Des Heules at the Northeast Vildlife Conference in 1962. In the following table, these figures are compared with the results of the vinter aerial census made by a stratified sampling-- because of unsatisfactory weather conditions, it is "normal" for this Inventory also to fall somewhat short of the planned program.

Moose Population Estimates

\begin{tabular}{lccc} 
Year & Winter Census & Pellet Plots & Comparison Factor \\
\cline { 2 - 3 } 1964 & $704 *$ & $1638 \%$ & 2.3 \\
1965 & $848 *$ & $1803 *$ & 2.1 \\
1966 & 721 & 1598 & 2.2 \\
1967 & 530 & 2406 & 4.5 \\
1968 & 1015 & 2224 & 2.2 \\
1969 & 1150 & 2329 & 2.0 \\
1970 & 944 & $-\cdots$ &.-- \\
* non-stratified & & &
\end{tabular}


It has become evident that the moose-density habitat stratification pattern for the rinter count should sometimes be modified according to snow-depth conditions. That Holfe did this with some success is indicated by the relative sonsistency of his results in 1968 and 1969 , which a difference in about 30 inches in snow depth greatly affected the distribution of moose.

The most significant feature in the above table is the $\infty n-$ sistency of the comparison factor. Our best estimate of the meaning of these figures is that the rinter aerial count is coming fairly close to the actual population, indicating an average miduinter herd of around 900 moose. The pellet plot conversion is too high for our conditions and the method needs a more realistic calibration; however these surveys do indicate relative densities from year to year. The indications are that, if possible, this work should be continued.

He have become increasingly dissatisfied with the sumer calf count as an index of moose reproduction, but lacking better methods we will continue to summarize our field observations in these terms. From late liay through the end of August in 1969, field personnel recorded 230 sightings of moose thich may be categorized as follows :

Hiales Females Calves Total Cowsw/calves Cows w/twins $\begin{array}{llllll}102 & 97 & 31 & 230 & 245 & 35\end{array}$

of the females seen, 12 could be identified as yearlings. The ratio of calves to adult females was 36:100.

These figures suggest that recruitment in the moose herd in 1969 was somevhat lover than that observed in former years. However, it is doubtful if such a conclusion can be reached reliably because of sampling error and variables in moose behavior (e.g. the hiding of calves) which create biases we do not understand. Past experience indicates a higher degree of significance in the fall aerial count, which was taken 18-23 October, with lilliam J. Hartila piloting the Supercub on floats. Flying time in moose counting was approximately 24 hours. Sex and age distribution of the animals recorded were:

$$
\text { calparlicose: }
$$

Hales Females Calves Total Cowsw/calves Cowsw/turins

$\begin{array}{llllll}112 & 78 & 37 & 227 & 29 & 3\end{array}$

If it is assumed that yearling females comprised the same segment of the population as indicated by the summer count, the corrected index of productivity as expressed by the calf:adult cor ratio is $54: 100$. Actual natality, of course, is higher than this, and ve have no indication of the magnitude of early losses. However, in June two calves vere known to have been lost by drowning andione evidently was killed by wolves. 
A summary of the winter aerial census of moose for 1970 Indicates the marked differences in density that support the need for stratifying the sampling system. The high degree of mixture of vegetation types makes generalizing a necessity in setting up plots and brings about confusing variables is moose distribution from year to year.

Hidivinter Aerial iloose Census, 1970

Stratum

Area

(Sq mi)

1

2

3

4

IR
39.59

53.40

87.61

32.15

212.75 iloose

(per $s q \mathrm{ml}$ )

0.55

2.91

4.20

12.43

5.8
Calculated

total

22

155

368

400

945

Pop. est.: $945 \pm 240$

This census was taken in the first two veels of February under vhat may be considered slightly less than average snow depth conditions for the island (about 2 feet). It vas suboptimal in consideration of the physical condition of our pilot and observer much of the time and the prevalence of high wind that often reduced flying tine on a given day.

A record of particular interest was the finding in August of the skeletons of two dead bulls in the shallow vater of Nud Lake. These animals had locked antlers, and they had died during the 1968 rutting season. The younger animal (wear class VII) had the larger rack of the two (the older, wear class VIII). The skulls will be a part of the Park's museum collection and rill be displayed at the Rock Harbor visitor information center.

Further information on moose aging

As reported last year, our entire collection of moose specimens, for which teeth are available, has now been aged by the sectioning of the first molar and examination for annulations. Holfe's inspection of many teeth led hin to believe that of the six cheek teeth this one ( $(1)_{1}$ ) vas most satisfactory. It is the first molar to erupt and its root should show a complete set of cementum layers.

It might be assumed, however, that other molars or premolars could be used if their time of eruption vere taken into account. A systematic investigation of this idea was needed. Accardingly, Jim A. Bottorff undertook the problem as an undergraduate research project in the spring of 1970. Since it has been shown that maxillary teeth are more satisfactory for this purpose than mandibular teeth, the complete upper tooth rows of ten adult moose were used, five from the left and five from the right side. 
Bottorff sectioned and examined all 6 teeth from the ten specimens, with the following results: In all cases, the $\mathrm{H}$ produced the most easily read and reliable annual growth layer count? From this tooth, the cementum layers became less discernable and the count more erratic proceeding backward to $\mathrm{H}_{3}$ or forward to $\mathrm{P}_{2}$ (the second premolar is the first of the cheek teeth in the row and the first to erupt). A consistent correlation of the number of layers with the time of eruption was found in only 4 of the 10 specimens. Characteristically, $H_{3}$ is the lowest aged and least worn of the teeth, yet it is more ${ }^{3}$ difficult to read than lif. This work indicates strongly that the methods in use by Wolfe shoutd not be changed, and they will continue to be employed in determining the age of our collected specimens.

Beaver Studies, October 1969

From 3 through 23 October 1969, Philip C. Shelton livetrapped beavers and made ground surveys of beaver colonies on the northeast third of the island. On 19 and 21 October, he spent about 3.5 hours flying with Hillam Martila maling a partial count of active beaver colonies over the entire island. Results of this work are here compared with similar data from the intensive studies made of Isle Royale beavers in 1961-1963, as reported in Shelton's doctoral thesis of 1966 .

The most significant change detected since the earlier surveys was the increase of beavers by at least 25 percent. This increase vas primarily in inland colonies. Rock Harbor, Tobin Harbor, and the outlying islands in the northeast section had almost exactly the same number of active colonies in 1969 as in 1963. But on streams in this section and also over most of the rest of the island, the density of colonies had significantly increased. For example, Tobin Creek had five active colonies with food piles in 1969, whereas the most found there during the early 1960's was three.

The 1969 aerial survey of only 3.5 hours, plus three veeks of ground reconnaisance, brought the total number of known active colonies to 141, almost exactly the same as the 140 found in the more thorough survey of 1962, when 17 hours of flying time and some three months of ground surveys vere employed in what was thought to be an almost complete count. It is estimated that a few more hours of aerial survey in 1969 would have brought the number of known active colonies to between 175 and 200 , an increase of at least 25 percent over the 1962 figure.

That the increase was primarily in stream dwelling beavers is consistent with the hypothesis that the decline in beaver numbers in the late 1940's and early 1950's was caused by epizootic disease, probably tularemia. Harbor beavers would have been less susceptible to such a disease, and their numbers apparently did not drop as drastically as did those of stream and inland lake beavers. Consequently, they have continued to harvest their available foods, and 
nov have little left to sustain them, although they have demonstrated a remarkable tenacity and ability to thrive on birch and a variety of herbaceous and shrubby species growing close to shore.

During the $1960^{\prime} s$ beavers continued to reoccupy stream sites that were abandoned 10 to 20 years earlier. Although the most readily avallable stands of agpen were cut during this early occupancy, it appeared in the early 1960's that many abandoned sites had usable supplies of aspen and birch remaining and that food shortage was not the cause of the population Becline. In 1969 old-growth aspen was still being used, and preliminary analysis of 1969 observations does not indicate that the beavers vere traveling much greater distances for food than they were in the early 1960's. Many sites were found in 1969 where aspen was avallable within 50 to 100 feet of deep water, vell within safe foraging range for the animals. The rate of cutting appeared to be similar to that found in the early part of the decade. This cutting rate was much less than thet of the first occupancy of virgin stream sites during the 1930's and 1940's, when easily accessible trees especially aspens, were cut and wasted in large numbers. The trend toward greater efficiency of use with decreasing availability vas previously described.

Five colonies, all of which vere trapped in 1961-65, were trapped in October 1969. In 77 trap nights 23 different beavers were caught a total of 35 times. Colonies trapped and age classes of beavers caught were as follows:

\begin{tabular}{|c|c|c|c|c|c|c|}
\hline Colony & Adults & $\begin{array}{c}\text { Two-year- } \\
\text { olds } \\
\end{array}$ & Yearlings & Kits & Total & $\begin{array}{l}\text { No. trap } \\
\text { nights }\end{array}$ \\
\hline Carlbou-Rabbit Is. & 2 & 0 & 0 & 5 & 7 & 23 \\
\hline Lorelei Lane & 2 & 0 & 0 & 3 & 5 & 22 \\
\hline $\begin{array}{l}\text { lit. Franklin Trail } \\
\text { ponds }\end{array}$ & 1 & $1 *$ & 0 & 2 & 4 & 16 \\
\hline Baker Point & 0 & $2 * * *$ & 0 & 0 & 2 & 7 \\
\hline Moskey Creek & 2 & 0 & 2 & 1 & 5 & 9 \\
\hline Totals & 7 & 3 & 2 & 11 & 23 & 77 \\
\hline
\end{tabular}

* Hay have been three years old

it: One may have been three years old.

The scarcity of yearlings may Indicate an unproductive year in 1968 . Otherwise the age structure of the sample appears normal. 
Four of the 23 beavers had been tagged previously, but one, the adult female from the Caribou-Rabbit Islands colony, had lost her tags. (Beavers in this colony characteristically had tender ears and lost tags unusually often during tbe 1961-65 trapping period.) The three tagged beavers had all been tagged as $\mathrm{klts}$, one each in 1962,1963 , and 1965, and all appeared to be breeding adults in 1969. The 1963 and 1965 animals were in the same colony (Lorelei Lane) and probably were mates. The 1965 animal, the female, was born in this colony but the 1963 beaver was born in the adjacent CaribouRabbit Islands colony, over a mile southvest in Rock Harbor. The 1962 animal, a female, was born in the Hoskey Creek colony, where she was trapped in 1969.

The physical characteristics of these animals provided no evidence for a deterioratinn of the food supply, even on outlying Islands that have been occupied continuously for 15 years or more, during which time there has been no reganeration of the principle woody food species. Veights of adults and kits fell very close to the means or regression curve points for beavers of the same age and food habits in the 1961-63 sample:

leight in Pounds

Aspen fed
$\begin{aligned} & \text { Mt. Franklin Tr. \& } \\ & \text { Moskey Creek) }\end{aligned}$ $\begin{aligned} & \text { (Caribou-Rabbit Is. \& } \\ & \text { Lorelei Lane) }\end{aligned}$

Adu1ts

1961-63 mean

1969 mean

1969 range

1969 number

Kits (at 4.5 months)
42.0

44.5

$42-47.5$

3

12.1

13.2
36.4

36.5

$35-37$

4
1969 mean

1969 range

1969 number
$10.5-15$

3

.... $\quad 10.5-15$

9.8

9.6

$9-12$

8 


\section{Smaller Mammal Populations}

As noted previously, Wendel Johnson carried out a Ph.D. study of the smaller mammals of Isle Royale from June 1966 to October 1960. In August 1969 he submitted his thesis entitled, "Food habits of the Isle Royale red fox and population aspects of three of its principal prey species." Some of the highlights of his findings follow:

In vinter the fox 18 a scavenger on moose remains in the wake of the volf pack and a predator principally on snowshoe hares. With the disappearance of snow the percentage of other prey items increases and includes red squirrels, muskrats, deermice, and birds. Fox food habits vere assayed by scat analysis, and the occurence of hare remains from year to year was in accordance with hare numbers on the island. In August and September, as elsewhere, the fox becomes a fruit eater, and vild sarsaparilla is especially favored.

In 1966, at the beginning of this study, hares probably vere at their lowest point in ten years. In all three years summer trapping records showed a low production and survival of young, accounting for the low population of this period. The breeding season of the hare was from late larch to early August, and the mean litter size was fonnd to be 3.33. The average adult female produced 2 litters in a season. The best large area of habitat on the island is the 1936 burn. Staple foods in vinter vere birch and cedar and a variety of herbaceous plants in summer.

It may be added that the general prevalence of hare tracks at the time of the 1970 vinter study indicates that the snowshoe hare is now increasing on Isle Royale.

It does not appear that the red squirrel is heavily preyed upon by the fox or any other predator. The population appears to fluctuate with the production of cones, good crops occurring at intervals of from 2 to 6 years. In case of failure, the breeding stock of squirrels fails to function, and new litters are not conceived. This happened in marked degree in 1966. Then young are produced, survival is high. The survival rate of adults from year to year also is high. This species evidently produces only one litter per year in this environment. The red squirrel appears to have saturated its habitat on the island, and further increases probably are inhibited by behavioral and periodically by food factors. The species is most dense in coniferous forest and least plentiful in the sugar mapleyellow birch forest. It is likely that the 1936 burn will begin to support a fev squirrels as its growth continues. 
A remaricable feature of the Isle Royale animal community is the presence of only one species of mouse-size animal, the Canadian deermouse, Peromyscus m. maniculatus. Escept for wet areas, it occupies all the woody-plant habitats on the 1sland. It is not a staple food supply for the fox or for any other lenown predator. The breeding season lasts from late liarch to early October, and those females of the breeding stock that survive commonly produce 3 litters of 5 young each. First- and second-1itter young females may have 1 or 2 litters by the end of the eeason. This production pattern did not vary markedly for the three years of the study.

The colonization of Isle Royale by other species of small mammals, especially the voles, is a logical expectation for the future. The occurrence of more fires probably vill favor the increase of hares. If such an enemy as the marten vere reintroduced to Isle Royale, it is likely that a greater annual turnover rate would be established in the squirrel population. 


\author{
Purdue University \\ Department of Forestry \& Conservation \\ Lafayette, Indiana 47907
}

December 11, 1969

To the many people who vrote to me as a result of the TV program "The wolf men" on November $18,1969$.

Dear fellov conservationist:

Wy apologies for replying to your recent letter in this manner. When I returned from a ten-day absence from the campus, the accumulation of mafl relative to the volf documentary was much more than I have facilities to handle. Since many of you requested the same information, this mimeo may be a reasonably good expedient.

Status of the volf: In the 48 continguous states, the wolf is indeed an endangered species, and is so listed by the Secretary of the Interior. There are races in Canada and Alaska that are not in immediate danger. Do not be confused by people who call the coyote a "wolf". That is the origin of many wolf reports in Arkansas and other states. Coyote-dog crosses are a problem too-- many being large and yolf-like. In recent years there have been no reports of breeding volves in the states south of Canada other than in liinnesota (where there are several hundred) and the small population (averaging about two dozen) in Isle Royale National Park, which is a part of lifichigan. A few surviving "loners" evidently are living out their days in northern Hichigan and Hisconsin. Occasional anima1s cross the border from British Columbia or liexico, and there are several volves in Yellowstone. None of these is breeding, as far as anyone knows.

Holf-prey relations: Holves are big-game predators. The large grazing and browsing animals of the world depend on their natural enemies for population control. Then this control is ineffective, they build up and damage their ranges. The wolf exerts a strong and realistic culling effect because it takes mainly the old and weak animals (or the young when mothers are not healthy and capable of defending them). By protecting the range from over concentrations and by thinning the population, wolves are a long-term benefit to the animals that support them. The gun does not do the same kind of job. 
The move for protection: Large predators have been persecuted by man because in some situations they damage 21vestock, because people have misunderstood their ecological effect on prey, and simply because of unreasoning prejudice. The latter two factors are operating in lifnnesota where a limited rolf bounty is being paid (as a result of a strong political campaign last year). In Alaska a bounty is paid, and wolves are hunted from aircraft. I see from a news report that the Governor of Alaska has recelved some 2500 letters in protest of this situation since the documentary appeared in the 48 states. I am told that the progran did not appear in Alaska because an injunction had been secured against it. Many of you have asked, "What can I do?" The most immediate thing that any of us can do is to see that his viev points are known to the people who control the legal process. I learned yesterday that a bill is being introduced in both houses of Congress to make $1 \mathrm{t} 11$ legal to kill any animal from an aircraft. Protection came to the volf in Hichigan and Hisconsin too late to do any good. If more citizens had been active, this might not have happened.

Our Isle Royale study: The study of the wolf and moose that we have carried out in Isle Royale National Park (Lake Superior) for the past 10 years has made use of the only area in the vorld where these two species are living together undisturbed by either hunting or predator control. liidwinter populations of wolves have averaged about 24 . At that season there probably are 900-1000 moose on the 210-square-mile island. Both figures represent high populations. This study vas described in National Geographic for February, 1963. You can get David Hech's "The wolves of Isle Royale" from the Superintendent of Documents, Hashington, D. C. for $\$ 1.00$. It is the Seventh National Parks Fauna (1966) and is Dave's doctoral thesis-- he was my first student on this project. My present colleague in this work is Dr. Ilichael L. Wolfe, Jr., who vill be finishing his 3-year post-doctoral assigment (full-time) on this study next June. Much that ve have accomplished has depended on our bush-pilot and observer Donald E. liurray of Mountain Iron, Minnesota. Don is the best wolf tracker with an aircraft in the world. Both of these men appeared with me in the TV program, and I am sorry the other two vere not identified.

Haybe I should mention that universities do not have funds for studies like this, as some people assume. I have personally raised more than $\$ 200,000$ for this work in 10 years. We hope to stick it out for two or three more years, since some vonderful new problems have developed and need answers.

Last vinter the filming team from l.HG Documentary Division (Culver City, California) and the Canadian Film Board vas with us on the island for two weeks. This was our only major exception to a longstanding and necessary rule that ve can not make our vinter camp available to visitors. He are the only inhabitants of Isle Royale at that season, and all transport is by ski-plane. 
Question: There can I get a wolf to raise? I don't really know. Some people have obtained them from zoos. Raising a wolf is a job! You might like to read about Lois Crisler's experiences in "Artic Hild".

Personal comment: It is uonderful to witness hov many people are concerned with the preservation of wildlife and natural areas, and how they reveal themselves after something like Irwin Rosten's (IIGI) program on the wolves. It is obvious that the presentation of factual material without preaching or comment allowed people to reach their oim conclusions about the need for protecting this great animal. Some of you have asked my opindon on how wolves should be handled under modern onditions. Here are a few ideas:

For now, I think wolves could hold their orm and probably rould not be a nuisance if both lifnnesota and Alaska put them on the game list, required a license, set a 1 imit of one per hunter, and set the open season to colncide with big-game hunting. This is being done by some states vith the mountain lion in the lest. It is the bounty, poisoning, alrcraft hunting, and snaring that have been unreasonably destructive of the wolf. It is entirely possible that wolves will need greater protection later, but for now, the above vould represent real progress.

Thank you for letting me hear from you, and I hope you are not offended by this mass-production reply. Our vould is getting too much that way, isn't it?

Sincerely,

Durvard L. Allen, Professor of Hildife Ecology

DLA/cif 